\title{
Towards elucidation of the lignin degradation pathway in actinomycetes
}

\author{
Bernard Godden, ${ }^{1}$ Andrew S. Ball,${ }^{2} \dagger$ P. Helvenstein, ${ }^{1} \ddagger$ Alan J. MCCarthy ${ }^{2 *}$ \\ and MiCHEL J. PENNINCKX ${ }^{1}$ \\ ${ }^{1}$ Unité de Physiologie et Écologie Microbienne, Laboratoire de Microbiologie, Faculté des Sciences, \\ Université Libre de Bruxelles, CERIA 1, B-1070 Brussels, Belgium \\ ${ }^{2}$ Department of Genetics and Microbiology, Life Sciences Building, University of Liverpool, PO Box 147, \\ Liverpool L69 3BX, UK
}

(Received 9 March 1992; revised 27 July 1992; accepted 3 August 1992)

\begin{abstract}
Six biodegradative actinomycete strains were grown on a dimeric model lignin compound of the $\beta$-aryl ether type. Although only two strains, Thermomonospora mesophila and Streptomyces badius, utilized the compound as a carbon and energy source and produced substantial amounts of monomeric products, all of the strains could demethylate the substrate and oxidize $\mathrm{C} \alpha$ on the phenylpropane side-chain. Streptomyces sp. ECl produced small amounts of aromatic acids and unidentified lignin-derived products when grown on straw. This organism also produced cell-bound demethylase requiring $\mathrm{H}_{2} \mathrm{O}_{2}$ and $\mathrm{Mn}^{2+}$, protocatechuate 3,4-dioxygenase and $\beta$ carboxymuconate decarboxylase activity in response to growth on low-molecular-mass aromatic compounds but not lignocellulose or its polysaccharide components. Extracellular peroxidase and catalase activity were detected in all of the strains. These data are used to propose a scheme by which actinomycete attack of the lignin component of plant biomass can be envisaged.
\end{abstract}

\section{Introduction}

The detailed biochemistry of lignin degradation is beginning to be resolved in the wood-rotting fungus Phanerochaete chrysosporium. This organism can extensively depolymerize lignin by secreting oxidative enzymes, of which the peroxidases have been identified as the most important. Multiple forms of lignin peroxidase (Farrell et al., 1989) and manganese peroxidase (Gold $e t$ al., 1989) are known to be involved, together with glyoxal oxidase, which is reponsible for the generation of $\mathrm{H}_{2} \mathrm{O}_{2}$ (Kersten \& Kirk, 1987) essential to the degradation process. Lignin degradation occurs only during secondary metabolism in $P$. chrysosporium, triggered by nutrient (particularly nitrogen) starvation (Keyser et al., 1978), and this has helped in the implication of particular enzyme species in lignin attack. Lignin degradation by bacteria is by comparison poorly understood; it appears to be a primary metabolic process which results in

\footnotetext{
* Author for correspondence. Tel. 051794 4413; fax 0517945106.

$\dagger$ Present address: Biology Department, University of Essex, Colchester, Essex CO4 3SQ, UK.

$\ddagger$ Present address: Pfizer Corporation, Ave. L. Theodor 102, 1090 Brussels, Belgium.
}

modification and solubilization rather than depolymerization on any significant scale (for a review see Zimmermann, 1990).

The structural complexity of native and extracted lignins often requires that alternative substrates be used as indicators of degradative ability. These substrates have included simple monomeric aromatic compounds (Eriksson et al., 1984; Sutherland et al., 1983), but synthesized dimeric and trimeric aromatic ring compounds containing linkages similar to those found in native lignin (Crawford et al., 1975; Gold et al., 1984) are more relevant. Enzymes directly involved in attacking these compounds include not only phenol oxidases such as peroxidases and laccases, but also dioxygenases such as protocatechuate dioxygenase. In native lignin, the arylglycerol- $\beta$-aryl ether $(\beta-\mathrm{O}-4)$ bond accounts for almost $50 \%$ of the phenylpropane linkages (Adler, 1982) and its cleavage is thought to be crucial to depolymerization. The extracellular lignin peroxidases of $P$. chrysosporium have been shown, using model compounds, to cleave not only this bond (Kirk et al., 1986; Miki et al., 1986), but also several others, including diaryl propane, $\alpha$-aryl and biphenyl linkages (Tien, 1987). A number of prokaryotes can cleave $\beta$-O-4 linkages in model compounds (see Zimmermann, 1990) and in Streptomyces

Abbreviation: APPL, acid-precipitable polymeric lignin. 
viridosporus, this activity was exhibited by a partially purified isoform of extracellular peroxidase (Ramachandra et al., 1988).

Actinomycetes have received the most attention of the biodegradative prokaryotes. Their hyphal growth form is well-suited to the colonization of plant biomass and they secrete a range of enzymes active against lignocellulose. While they can generate some ${ }^{14} \mathrm{CO}_{2}$ from $\left[{ }^{14} \mathrm{C}\right]$ ligninlabelled lignocellulose preparations, their ability to solubilize a lignin-rich fraction of the substrate is more impressive (for a review see McCarthy, 1987). Whether this solubilization of lignocarbohydrate involves any direct attack on polyphenolic lignin is equivocal (Ball et al., 1989) but the product, which can be recovered from culture supernatants by simple acid precipitation (Crawford et al., 1983), has a number of interesting and potentially exploitable properties (Crawford et al., 1984; Ball et al., 1990). Subsequent to the discovery of lignin peroxidase in $P$. chrysosporium (Tien \& Kirk, 1983), Crawford and coworkers have described and partially characterized extracellular peroxidases in Streptomyces strains classified as ligninolytic (Ramachandra et al., 1988; Adhi et al., 1989; Lodha et al., 1991). However, extracellular peroxidase activity is not restricted to those actinomycetes for which there is good evidence of lignindegrading ability (Ball et al., 1990; Wang et al., 1990), and indeed preliminary screening shows that peroxidases are common in this group of organisms (D. Mercer \& A. J. McCarthy, unpublished data). That lignocellulose degradation involves the activity of a range of hydrolytic and oxidative enzymes is established; in the work described here, biodegradative actinomycete strains were examined using different methods and substrates with a view to clarifying the enzymology of attack on the lignin component.

\section{Methods}

Strains and growth conditions. Actinomycete strains (Table 1) were maintained as spore suspensions and hyphal fragments in $20 \%(\mathrm{v} / \mathrm{v})$ glycerol at $-70^{\circ} \mathrm{C}$, and routinely cultured on L-agar (Hopwood et al., 1985). Distilled-water suspensions of sporulating growth were used to inoculate shake flasks containing basal salts medium supplemented with ball-milled wheat straw (Ball \& McCarthy, 1988). Conical flasks $(250 \mathrm{ml})$ containing $50 \mathrm{ml}$ growth medium were used throughout. In cultures examined for the utilization of lignin-related compounds, ballmilled straw was replaced by $0.01 \%$ of the appropriate model compound. Cultures were incubated with shaking at 200 r.p.m. for up to $12 \mathrm{~d}$ at $30^{\circ} \mathrm{C}, 37^{\circ} \mathrm{C}$ or $50^{\circ} \mathrm{C}$, as appropriate (Ball et al., 1989). Cultures were harvested by centrifugation, washed twice in distilled water and dried at $80^{\circ} \mathrm{C}$ overnight for the determination of growth yields by dry weight measurement. For experiments on the induction of enzyme production in Streptomyces strain EC1, the basal medium and methods of Godden et al. (1989) were used.

Lignin model compounds. 3,4-dimethoxyphenyl- $\omega$-(2-methoxyphenoxy)acetophenone (compound 1), 1-(3,4-dimethoxyphenyl)-2-(2-meth- oxyphenoxy)ethanol (compound 2), and 4-hydroxy-3-methoxyphenyl$\omega$-(2-methoxyphenoxy)acetophenone (compound 3) were synthesized as described elsewhere (Betts \& Dart, 1988), and kindly supplied by Dr W. B. Betts, Department of Biology, University of York, UK. Their structures are illustrated in Fig. 1.

Recovery of degradation products. Cultures grown on model dimers were harvested by centrifugation at $10000 \mathrm{~g}$ for $10 \mathrm{~min}$ at $4{ }^{\circ} \mathrm{C}$ and the supernatants acidified to $\mathrm{pH} 2$ with $0.5 \mathrm{M}-\mathrm{HCl}$ before extraction twice with ethyl acetate. The extracts were evaporated to dryness using a rotary evaporator and the residue dissolved in a small volume of acetone for application to thin-layer chromatography (TLC) plates.

Cultures grown on ball-milled wheat straw $(0 \cdot 1 \%)$ were centrifuged at $27000 \mathrm{~g}$ for $10 \mathrm{~min}$, acidified to $\mathrm{pH} 1.5$ with $0.5 \mathrm{M}-\mathrm{H}_{2} \mathrm{SO}_{4}$ and then recentrifuged to remove precipitate from the supernatant. The supernatant was extracted twice with diethyl ether or ethyl acetate and evaporated to dryness before redissolving in the appropriate solvent for further analysis.

Thin-layer chromatography (TLC). Samples were spotted on silica plates (Silica Gel 60F-254, Merck) and the products separated using toluene/methanol/ethyl acetate $(90: 16: 8$, by vol.), toluene/ethyl acetate $(90: 10, v / v)$, or chloroform/methanol $(97: 3, v / v)$. Compounds containing aromatic rings were visualized under short-wave UV light.

For analysis of straw degradation products, benzene/acetic acid/ dioxane $(90: 5: 25$, by vol.) or acetone/propylene glycol $(90: 10, \mathrm{v} / \mathrm{v})$ were used to resolve components. Non-fluorescent compounds were detected by spraying the plates with an indicator comprising $\mathrm{K}_{3} \mathrm{Fe}(\mathrm{CN})_{6}(1.0 \% \mathrm{w} / \mathrm{v})$ and $\mathrm{FeCl}_{3}(1.0 \%$, w/v) mixed in equal volumes immediately prior to use (Eggen, 1969).

High-performance liquid chromatography (HPLC). Straw and model compound degradation products were also detected and identified using HPLC on a $\mu$ Bondapak $\mathrm{CN}$ column eluted with methanol/water/ acetic acid $\left(20: 79: 1\right.$, by vol.) at a flow rate of $0.5 \mathrm{ml} \mathrm{min}^{-1}$. The column was loaded with ethyl acetate extracts $(1 \mathrm{ml})$ of culture supernatants and elution monitored at $254 \mathrm{~nm}$.

Enzyme preparations. Cultures were centrifuged at $10000 \mathrm{~g}$ for $10 \mathrm{~min}$ at $4{ }^{\circ} \mathrm{C}$ and the supernatant fluids assayed for the presence of enzyme activities or concentrated by ultrafiltration. Culture supernatants were filtered under pressure using a $10 \mathrm{kDa}$ molecular mass cut-off filter (Amicon PM10) until a 20-fold reduction in supernatant volume had been achieved. Intracellular enzyme activities were assayed in culture extracts prepared by sonication in an ice bath $(3 \times 30 \mathrm{~s}$ at $18 \mu \mathrm{m}$ peak to peak) of washed culture pellets. Protein concentration was determined by the Lowry method.

Enzyme assays. Veratryl alcohol oxidation was measured by the formation of the product, veratraldehyde (Ball et al., 1989). Peroxidase activity was recorded by measuring the formation of the dopachrome pigment $\left(A_{470}\right)$ from L-DOPA (Sigma) (Deobald \& Crawford, 1987). Catalase activity was measured by recording $\mathrm{O}_{2}$ production by culture supernatants from selected strains grown on straw medium, using an oxygen electrode. Concentrated supernatant $(200 \mu 1)$ and potassium

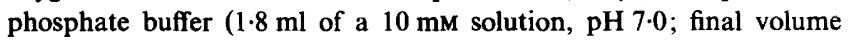
$2.0 \mathrm{ml}$ ), were maintained at $37^{\circ} \mathrm{C}$, and the reaction started by the addition of $10 \mu \mathrm{l}$ of $10 \mathrm{mM}-\mathrm{H}_{2} \mathrm{O}_{2}$.

Protocatechuate 3,4-dioxygenase (EC 1.13.11.3) activity was assayed in crude cell extracts according to the spectrophotometric procedure of Stanier \& Ingraham (1954) with slight modifications as follows. Extracts were prepared by sonication $\left(10 \mathrm{~min}\right.$ at $4{ }^{\circ} \mathrm{C}$; Vibracell 500, Ultrasonic Processor) of Streptomyces sp. ECl culture pellets obtained by membrane filtration (Millipore, $0.45 \mu \mathrm{m}$ pore diameter) of 2-d-old cultures $(200 \mathrm{ml})$ prepared as described above, and resuspended in $5 \mathrm{ml} 50 \mathrm{~mm}$-sodium phosphate buffer ( $\mathrm{pH} \mathrm{7.5)}$. The assay was optimized at $30^{\circ} \mathrm{C}$ under these conditions. Increase in 


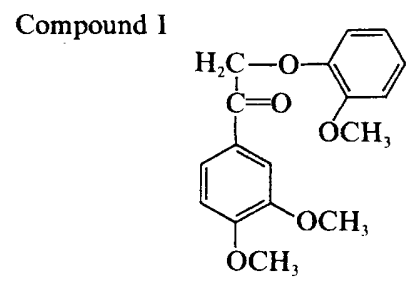<smiles>COc1ccc(C(O)COc2ccccc2OC)cc1OC</smiles>

Compound III<smiles>COc1cc(C(=O)COc2ccccc2OC)ccc1O</smiles>

Fig. 1. Structures of dimeric lignin model compounds used.

Table 1. Degradation of lignin model dimer (compound I) by actinomycetes

\begin{tabular}{|c|c|c|c|c|c|c|}
\hline \multirow[b]{2}{*}{ Strain* } & \multicolumn{2}{|c|}{$\begin{array}{l}\text { Growth }[\mu \mathrm{g} \text { dry weight } \\
\left.\quad(\mathrm{ml} \text { culture })^{-1}\right]_{\dagger}^{\dagger}\end{array}$} & \multicolumn{4}{|c|}{ Products detected by TLC $\ddagger$} \\
\hline & Basal medium & $\begin{array}{l}\text { Basal medium } \\
+ \text { compound I }\end{array}$ & $\begin{array}{l}\text { Compound I } \\
\text { (54) }\end{array}$ & $\begin{array}{c}\text { Compound III } \\
(45)\end{array}$ & $\begin{array}{l}\text { Vanillic } \\
\text { acid } \\
(49)\end{array}$ & $\begin{array}{l}\text { Protocatecheuic } \\
\text { acid } \\
(67)\end{array}$ \\
\hline Streptomyces sp. EC1 & 20 & 25 & + & + & - & - \\
\hline Streptomyces sp. EC22 & 27 & 10 & + & + & - & - \\
\hline S. cyaneus MT813 & 11 & 21 & + & + & - & - \\
\hline Amycolata autotrophica DSM 43099 & 41 & 30 & + & + & - & - \\
\hline
\end{tabular}

* For strain designations and sources refer to Ball et al. (1989).

$\dagger$ Growth yield results are means of duplicate experiments. The variation was $<5 \%$.

$\ddagger$ Identical product profiles were identified by the different solvent systems; $R_{F}$ values for toluene/methanol/ethyl acetate $(90: 16: 8)$ are given in parentheses. The structures of compounds I and III are given in Fig. 1.

absorbance was found to be linear with time up to $10 \mathrm{~min}$ as a function of the amount of protein in the enzyme preparation. A subsequent decrease in absorbance, and attributable to $\alpha$-carboxymuconate decarboxylase (MacDonald et al., 1954), was always shown when the dioxygenase was detected. Units of protocatechuate dioxygenase activity were expressed as increase in $A_{270} \mathrm{~min}^{-1}$.

Aromatic methylester demethylase, $\mathrm{H}_{2} \mathrm{O}_{2}$-dependent and activated by $\mathrm{Mn}^{2+}$, was assayed in crude cell extracts by a slight modification of the procedure of Huynh \& Crawford (1985). The sodium tartrate buffer (pH 5.0) used in the original procedure was replaced by sodium phosphate buffer $(100 \mathrm{mM} ; \mathrm{pH} \mathrm{7.5})$, in the presence of $50 \mathrm{~mm}-\mathrm{H}_{2} \mathrm{O}_{2}$ and $100 \mathrm{~mm}-\mathrm{MnSO}_{4}$. No activity was detected at $\mathrm{pH}<6.5$ and $\mathrm{pH}>8 \cdot 3$. The assay was shown to be linear with time for up to $10 \mathrm{~min}$, as a function of protein concentration. The model substrates, 2methoxy-3-phenylbenzoic acid (M1) and methyl-2-methoxy-3-phenyl benzoic acid (M4) were prepared according to Huynh \& Crawford (1985). Units of demethylase activity were expressed as an increase in $A_{310}$ (M1) or $A_{320}(\mathrm{M} 4) \mathrm{min}^{-1}$.

For calculation of specific enzyme activities in Streptomyces sp. EC1, protein was determined by the Kjeldahl procedure $(\mathrm{N} \times 6.25)$ on cultures harvested by centrifugation at $27000 \mathrm{~g}$ for $15 \mathrm{~min}$.

Gel electrophoresis. Peroxidase activities were identified in concentrated culture supernatants by isoelectric focusing and native polyacrylamide gel electrophoresis. The Phast system (Pharmacia) was used and separation of proteins achieved under the conditions recommended by the manufacturer. Peroxidase bands were detected using a solution of L-DOPA/aminoantipyrine/ $\mathrm{H}_{2} \mathrm{O}_{2}$ as described by Adhi et al. (1989).

\section{Results}

Degradation of lignin model compounds by actinomycetes

Six actinomycete strains of physiological and taxonomic diversity, and for which there is evidence of activity against lignin-related compounds (Ball et al., 1989), were grown in shake-flask cultures containing the nonphenolic model compound I (Fig. 1) as the primary carbon source. Determination of growth yields revealed that only three strains could be considered as having substantially degraded the substrate (Table 1). Streptomyces badius 252 and Thermomonospora mesophila DSM 43048 produced a three- to fourfold-increase in yield when compound I was included in the basal medium and these were also the only two cultures in which monomeric products (vanillic acid and protocatechuic acid) were detected, demonstrating that cleavage of the $\mathrm{C} \alpha-\mathrm{C} \beta$ bond had occurred (Table 1). In all cultures, a large amount of the substrate, compound I, remained undegraded and all of the strains, whether capable of growing on this substrate or not, were able to demethylate compound I to produce detectable amounts of compound III (Table 1). 
In addition to demethylation, oxidation of $\mathrm{C} \alpha$ on the phenylpropane chain would be an important preliminary reaction in lignin degradation and evidence for this was examined by growing strains on basal medium containing compound II (Fig. 1). In all of the cultures, again irrespective of the strain's ability to grow on compound I, both compound I and compound III were detected by TLC in culture supernatants.

The products of actinomycete growth on compound I were further identified by reverse-phase HPLC analysis of culture supernatant extracts. Results similar to those produced by TLC analysis were observed with $T$. mesophila and $S$. badius, although compounds I and III could not be differentiated from one another. The presence of small amounts of unidentified compounds, possibly including guaiacol, was also revealed. The greater sensitivity of HPLC showed that $A$. autotrophica and Streptomyces sp. EC22 were also capable of $\mathrm{C} \alpha-\mathrm{C} \beta$ bond cleavage, a fact which measurement of growth yields and product analysis by TLC had failed to demonstrate. There was also some evidence that monomeric products had been generated by $S$. cyaneus; degradation products produced by Streptomyces $\mathrm{sp}$. EC1 were not analysed by HPLC. Adequate controls were always included to ensure that small amounts of product were not the result of chemical oxidations.

\section{Aromatic products of straw degradation by Streptomyces} sp. ECI

This strain was cultured in shake-flasks of medium containing ball-milled wheat straw as substrate, to determine whether any low-molecular-mass aromatic compounds resulting from degradation of the lignin component could be detected in the culture supernatant. The application of both TLC and HPLC, with identification of compounds by UV spectroscopy and comparison with appropriate standards, revealed that Streptomyces sp. ECl produced four major lignin-derived products: syringic acid, ferulic acid, vanillin and vanillic acid (data not shown). These were first detected after $36 \mathrm{~h}$ growth on straw and were present in the culture supernatant, together with small amounts of other unidentified aromatic compounds, throughout the $7 \mathrm{~d}$ culture period.

\section{Identification of enzyme activities possibly involved in lignin degradation}

Extracellular peroxidase and catalase activity were detected in all of the strains studied here, and veratryl alcohol oxidase only in those strains previously shown to produce veratraldehyde in culture (Ball et al., 1989). The concentrated straw culture supernatants of $S$. badius and Streptomyces sp. ECl were also loaded onto mini isoelectric focussing gels (Pharmacia Phast system) developed as zymograms to detect bands of peroxidase activity. Three isoforms of peroxidase were observed for each strain, but the poor gel quality and band resolution preclude conclusions beyond this basic observation. Similar peroxidase isoform patterns have been reported previously for both $S$. viridosporus $\mathrm{T} 7 \mathrm{~A}$ and the $S$. badius strain 252 included in this study (Adhi et al., 1989).

A more detailed analysis of enzyme profiles and regulation of their production was undertaken in Streptomyces sp. EC1. In addition to the extracellular activities outlined above, cell-associated enzymes of the $\beta$-ketoadipate pathway (protocatechuate dioxygenase and $\beta$-carboxymuconate decarboxylase) were identified. Interestingly, a demethylating activity strictly dependent on $\mathrm{Mn}^{2+}$ and $\mathrm{H}_{2} \mathrm{O}_{2}$ was also discovered in this organism. 2-Methoxy-3-phenylbenzoate and methyl-2-methoxy-3phenylbenzoate were used as substrates for demethylase because the reaction produced 3-phenylsalicylate which accumulated and could be quantitatively determined. Vanillic acid, the most oxidized and methylated compound that we detected in culture supernatants, is a possible substrate for the demethylase. Indeed, UV optical activity of vanillic acid virtually disappeared after incubation with a cellular extract, but only in the presence of $\mathrm{Mn}^{2+}$ and $\mathrm{H}_{2} \mathrm{O}_{2}$ and for cells grown on substrates which appeared to induce demethylase production (Table 2). The disappearance of UV optical activity is most probably attributable to the conjugate actions of protocatechuate dioxygenase and $\beta$-carboxymuconate decarboxylase (see Table 2).

To study the physiological regulation of enzyme production, Streptomyces sp. ECl was grown in a mineral salts medium containing glycerol $(0 \cdot 2 \%)$ as sole carbon source (Godden et al., 1989) and then transferred to media containing different carbon sources. Enzyme activities were determined after $24 \mathrm{~h}$ incubation, which corresponded to the lag phase preceding resumption of growth after transfer from glycerol medium, as previously determined (Godden et al., 1989). The results are presented in Table 2 and demonstrate the extracellular and inducible nature of peroxidase activity in this organism. This activity was found to be strictly $\mathrm{H}_{2} \mathrm{O}_{2}$ dependent, and its production was induced by growth on straw, Indulin AT (Kraft lignin), syringic acid, 3,4dimethoxycinnamic acid and vanillic acid. These compounds contain lignin or are lignin-related, but other such substrates (APPL, ferulic acid and 3,5-dimethoxy4-hydroxycinnamic acid) did not appear to induce peroxidase production. Xylan and carboxymethylcellulose, which can be regarded here as representing the polysaccharides of lignocellulose, had no detectable inducing effects. The other three cell-associated enzymes were not significantly induced by lignocellulose and 
Table 2. Enzyme induction in Streptomyces strain ECI

\begin{tabular}{|c|c|c|c|c|}
\hline \multirow[b]{2}{*}{ Growth substrate* } & \multicolumn{4}{|c|}{ Specific activity $\left[\mathbf{U}\right.$ (mg cellular protein) $\left.{ }^{-1}\right] \dagger$} \\
\hline & $\begin{array}{l}\text { Peroxidase } \\
\text { (E) }\end{array}$ & $\begin{array}{l}\text { Demethylase } \\
\text { (CB) }\end{array}$ & $\begin{array}{l}\text { Protocatechuate } \\
\text { 3,4-dioxygenase } \\
\text { (CB) }\end{array}$ & $\begin{array}{c}\beta \text {-Carboxymuconate } \\
\text { decarboxylase } \\
\text { (CB) }\end{array}$ \\
\hline Straw & $0 \cdot 11$ & 0.43 & 0.50 & + \\
\hline Straw + glycerol & ND & $0 \cdot 19$ & ND & ND \\
\hline Indulin AT & $0 \cdot 10$ & 0.44 & 0.50 & + \\
\hline Ferulic acid & ND & 0.49 & $5 \cdot 80$ & + \\
\hline Syringic acid & $0 \cdot 10$ & ND & ND & ND \\
\hline 3,4-Dimethoxycinnamic acid & 0.05 & ND & $0 \cdot 45$ & + \\
\hline 3,5-Dimethoxy-4-hydroxycinnamic acid & ND & ND & 0.62 & + \\
\hline Vanillic acid & 0.05 & $0 \cdot 45$ & $4 \cdot 50$ & + \\
\hline Protocatechuic acid & ND & ND & $6 \cdot 20$ & + \\
\hline
\end{tabular}

* All substrates were added to the basal medium (Godden et al., 1989) to a final concentration of $0 \cdot 2 \%$.

+ Experiments were done in triplicate (standard deviations were all within $10 \%$ of the mean value presented). E, extracellular; CB, cell-bound. ND, Not detected; + , detected but not quantified (see Methods).

related substrates, but as expected were induced by various low-molecular-mass aromatic compounds (Table 2).

\section{Possible catabolic pathway for lignin and related compounds}

The pathway for the utilization of dimeric $\beta$-aryl ether linked methoxylated aromatic compounds by actinomycetes can be deduced from the results reported here and is similar to that found in $S$. viridosporus (Crawford, 1986). This forms the core of a proposed scheme by which actinomycete attack of the lignin component of plant biomass can be envisaged. This scheme is presented in Fig. 2 and further discussed below.

\section{Discussion}

Many actinomycetes can solubilize lignocarbohydrate from substrates such as straw and there is also some evidence for depolymerization of the lignin fraction (Ball et al., 1990). Early steps in actinomycete-mediated attack on lignin are largely unknown but may involve extracellular peroxidases as has been established for white-rot fungi (see Kirk \& Farrell, 1987) and subsequently suggested for streptomycetes (Ramachandra et al., 1987, 1988). Studies directed at elucidating the mechanisms of lignin degradation by actinomycetes have tended to centre on the solubilization of lignocarbohydrate as an acid-precipitable complex, APPL (see Zimmermann, 1990). Our recent work has specifically addressed the relationship between lignin degradation and APPL production, and has led us to conclude that an ability to attack complex or even simple lignin-related compounds is not required for the latter (Ball et al., 1989) although the generation of APPL is an interesting and exploitable phenomenon (Crawford et al., 1984; Ball et al., 1990). Here, we have concentrated on the production of biochemical evidence for reactions, by analysis of endproducts, and for oxidative enzymes, by assaying for their presence in both extracellular and cell-bound fractions, that are likely to contribute to lignin degradation per se.

Degradation of the dimeric lignin model compound I was unequivocally demonstrated in $T$. mesophila and $S$. badius. More sensitive analysis, i.e. the use of reversephase HPLC, confirmed this and provided evidence that the other strains were capable of attack beyond simple demethylation. Furthermore, all of the strains studied could generate compounds I and/or III from compound II. In summary therefore, there are three elements to the degradation of $\beta$-O-4-linked dimeric lignin model compounds reported here: demethylation of aromatic ring structures; oxidation of $\mathrm{C} \alpha$ to introduce a carbonyl group; and $\alpha-\beta$ cleavage to monomeric products. These are also reactions that have been described in other actinomycetes and bacteria (see Vicuña, 1988) and in fungi (Betts \& Dart, 1988). C $\alpha$ oxidation in particular may have implications for in situ lignin degradation, beyond its role as a prerequisite for $\alpha-\beta$ cleavage. It has been suggested that detection of a strong carbonyl peak in ${ }^{13} \mathrm{C}$ NMR spectra of APPL produced by $T$. mesophila was due to $\mathrm{C} \alpha$ oxidation that would contribute to increased lignin solubility (McCarthy et al., 1986). In the ligninolytic fungus Phanerochaete chrysosporium, $\mathrm{C} \alpha$ oxidation is a prominent reaction which Fenn \& Kirk (1984) suggested would enhance the accessibilty of lignin to enzymic attack. Whether actinomycetes can utilize $\beta$ O-4 lignin model compounds in vivo, i.e. as carbon 


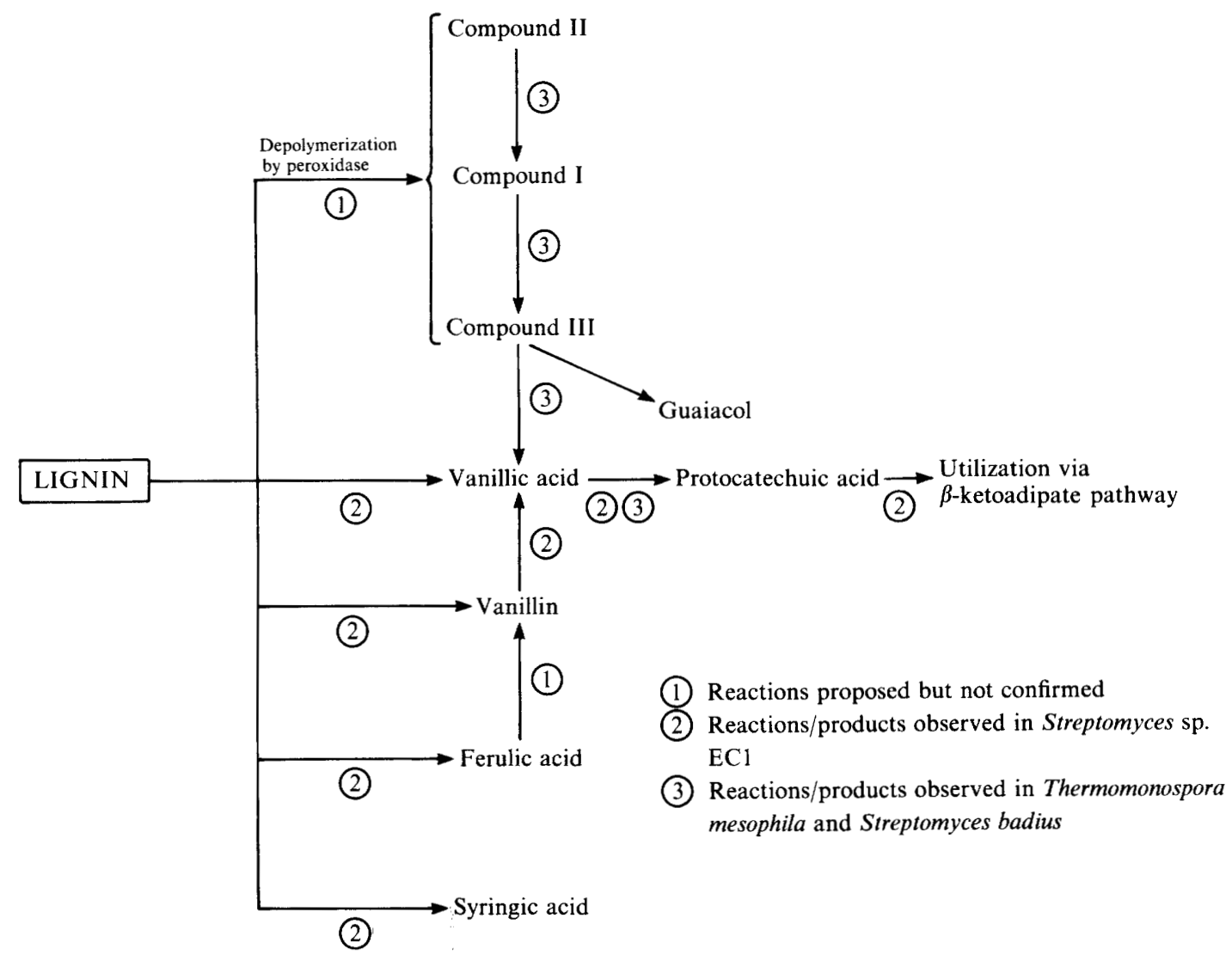

Fig. 2. Proposed scheme for degradation of lignin and related compounds by actinomycetes.

sources, has been equivocal (Ruttiman et al., 1987; Zimmermann, 1990). Clearly, the conclusion that $S$. badius and T. mesophila can use dimeric model compound $I$ as a source of carbon and energy (Table 1) is further supported by the fact that TLC analysis sufficed to detect degradation products in the culture supernatants of these, but not the other strains.

The generation of utilizable carbon sources from lignin requires the action of extracellular, or possibly surface-bound, enzymes. Peroxidases are the current prime candidates and these enzymes are secreted by actinomycetes in multiple forms. There is evidence that peroxidase isoforms are related, within and between Streptomyces strains (Magnuson et al., 1991) and the purification of actinomycete extracellular peroxidases to homogeneity in sufficient quantities for detailed biochemical and molecular characterization is one of our research priorities. That actinomycete extracellular peroxidases attack and depolymerize lignin is possible but not yet established. While not detracting from the potential role of peroxidases as initial agents of attack on lignin, the intimate involvement of other actinomycete enzymes which disrupt lignocarbohydrate structure should not be ignored (Donnelly \& Crawford, 1988;
Bachmann \& McCarthy, 1991; Faulds \& Williamson, 1991). In particular, aromatic acids esterified to lignin can be released from lignocellulose by esterase activity (Donnelly \& Crawford, 1988) and could be the source of at least some of the vanillic acid and ferulic acid produced during growth of Streptomyces sp. ECl on straw.

The products of lignin fragmentation are available for the cellular carbon pool of actinomycetes during primary growth on lignocelluloses. However, estimates of the mineralization of the radiolabelled lignin fraction of straw by actinomycetes are low (McCarthy \& Broda, $1984)$ and the extent to which lignin degradation can contribute to the energy metabolism of these organisms remains to be addressed. Indulin AT, a Kraft lignin essentially free of carbohydrate, can be utilized but is not a good growth substrate for actinomycetes (Giroux et al., 1988; Ball et al., 1989; Godden et al., 1989). Both Indulin AT and wheat straw induced relatively high levels of extracellular peroxidase and cell-associated demethylase production by Streptomyces sp. EC1 but comparatively low amounts of dioxygenase and decarboxylase (Table 2). This supports the suggestion that lignin degradation does not contribute significantly to the carbon and 
energy metabolism of actinomycetes. Previous studies on Streptomyces sp. ECl have shown it to be capable of consuming approximately $20 \%$ of the hemicellulose fraction of straw in a $24 \mathrm{~h}$ batch culture, with a growth yield of $0.48 \mathrm{~g}$ dry weight per $\mathrm{g}$ xylan utilized (Godden $e t$ al., 1989). In fact, hemicellulose is the most degradable fraction of straw and the main growth substrate for this strain, and probably most other straw-degraders. Mineralization of the lignin fraction is likely to be in the form of metabolic co-oxidation, and optimal concentrations of inducers for enzymes of the $\beta$-ketoadipate pathway would probably never be achieved when growing on lignocellulose. Lignin degradation products present in small amounts in culture supernatants, described here and previously (Crawford, 1981) may nevertheless have an important role in regulation of growth and enzyme production when lignocellulose is the substrate. In Streptomyces sp. ECl at least, both cellulolysis and hemicellulolysis appear to be inducible by lignin-derived compounds in addition to the products of polysaccharide hydrolysis (Godden et al., 1989).

In conclusion, the main function of the scheme presented in Fig. 2 is to participate in the disorganization of lignocellulose structure to increase the accessibility of hemicellulose and cellulose. The scheme is derived from the results of experiments reported here, considered together with those previously published by others (Crawford, 1981, 1986; Donelly \& Crawford, 1988). Biodegradative actinomycetes are aerobic saprophytes whose primary substrate in soil is inevitably plant biomass. It is therefore not surprising that solubilization of lignocarbohydrate to produce a humic-acid-like complex (APPL), secretion of peroxidases and attack on aromatic ring compounds are common traits in this group of organisms.

This research was supported by the European Economic Community Non-Nuclear Energy Programme.

\section{References}

Adhi, T. P., Korus, R. A. \& Crawford, D. L. (1989). Production of major extracellular enzymes during lignocellulose degradation by two streptomycetes in agitated submerged cultures. Applied and Environmental Microbiology 55, 1165-1168.

ADLER, E. (1982). Lignin chemistry: past, present and future. Wood Science and Technology 11, 169-218.

Bachmann, S. L. \& MCCarthy, A. J. (1991). Purification and cooperative activity of enzymes constituting the xylan-degrading system of Thermomonospora fusca. Applied and Environmental Microbiology 57, 2121-2130.

BALL, A. S. \& MCCARTHY, A. J. (1988). Saccharification of straw by actinomycete enzymes. Journal of General Microbiology 134, 21392147

BaLl, A. S., BetTs, W. B. \& McCARTHY, A. J. (1989). Degradation of lignin-related compounds by actinomycetes. Applied and Environmental Microbiology 55, 159-162.
Ball, A. S., Godden, B., Helvenstein, P., Penninckx, M. J. \& MCCARTHY, A. J. (1990). Lignocarbohydrate solubilization from straw by actinomycetes. Applied and Environmental Microbiology 56, 3017-3022.

BETTS, W. B. \& DART, R. K. (1988). The degradation of lignin-related compounds by Aspergillus flavis. Journal of General Microbiology 134, 2413-2420.

Crawford, D. L. (1981). Microbial conversions of lignin to useful chemicals using a lignin-degrading Streptomyces. Biotechnology and Bioengineering Symposium 11, 275-291.

CRAWFORD, D. L. (1986). The role of actinomycetes in the decomposition of lignocellulose. In Biological, Biochemical and Biomedical Aspects of Actinomycetes, pp. 715-728. Edited by G. Szabo, S. Biro \& M. Goodfellow. Budapest: Akademiai Kiado.

Crawford, D. L., Pometto, A. L., III \& Crawford, R. L. (1983). Lignin degradation by Streptomyces viridosporus: isolation and characterisation of a new polymeric lignin degradation intermediate. Applied and Environmental Microbiology 45, 898-904.

Crawford, D. L., Pettey, T. M., Thede, B. M. \& Deobald, L. A. (1984). Genetic manipulation of ligninolytic Streptomyces and generation of improved lignin-to-chemical bioconversion strains. Biotechnology and Bioengineering Symposium 14, 241-256.

CRAWford, R. L., KIRK, T. K. \& MCCOY, E. (1975). Dissimilation of the lignin model compound veraytrylglycerol- $\beta$-(o-methoxyphenyl)ether by Pseudomonas acidovorans: initial transformations. Canadian Journal of Microbiology 221, 577-579.

Deobald, L. A. \& CRaWford, D. L. (1987). Activities of cellulase and other extracellular enzymes during lignin solubilisation by Streptomyces viridosporus. Applied Microbiology and Biotechnology 26, 158163.

Donnelly, P. K. \& Crawford, D. L. (1988). Production by Streptomyces viridosporus T7A of an enzyme which cleaves aromatic acids from lignocellulose. Applied and Environmental Microbiology 54, 2237-2244.

EGGEN, K. (1969). Plant phenol derivatives. In Thin-layer Chromatography, pp. 686-706. Edited by E. Stan. Berlin: Springer-Verlag.

ERIKSSON, K. E., GuPTA, J. K., Nishidas, A. \& RAO, M. (1984). Syringic acid metabolism by some white-rot, soft-rot and brown-rot fungi. Journal of General Microbiology 130, 2457-2464.

Farrell, R. L., Murtagh, K. E., Tien, M., Mozuch, M. D. \& Kirk, T. K. (1989). Physical and enzymatic properties of lignin peroxidase isoenzymes from Phanerochaete chrysosporium. Enzyme and Microbial Technology 11, 322-328.

Faulds, C. B. \& Williamson, G. (1991). The purification and characterisation of 4-hydroxy-3-methoxycinnamic (ferulic) acid esterase from Streptomyces olivochromogenes. Journal of General Microbiology 137, 2339--2345.

FENN, P. \& KIRK, T. K. (1984). Effects of C $\alpha$-oxidation in the fungal metabolism of lignin. Journal of Wood Chemistry and Technology 4, 131-148.

Giroux, H., Vidal, P., Bouchard, J. \& Lamy, F. (1988). Degradation of Kraft Indulin lignin by Streptomyces viridosporus and Streptomyces badius. Applied and Environmental Microbiology 54, 3064-3070.

Godden, B., Legon, T., Helvenstein, P. \& Penninckx, M. (1989). Regulation of the production of hemicellulolytic and cellulolytic enzymes by a Streptomyces sp. growing on lignocellulose. Journal of General Microbiology 135, 285-292.

Gold, M. H., Enoki, A., Morgan, M. A., Mayfield, M. B. \& TANAKA, H. (1984). Degradation of the $\gamma$-carboxyl-containing diarylpropane lignin model compound 3-(4'-ethoxy-3'-methoxyphenyl)-2-(4"-methoxyphenyl) propionic acid by the basidiomycete Phanerochaete chrysosporium. Applied and Environmental Microbiology 47, 597-600.

Gold, M. H., WARIISHI, H. \& Valli, K. (1989). Extracellular peroxidases involved in lignin degradation by the white-rot basidiomycete Phanerochaete chrysosporium. In Biocatalysis in Agricultural Biotechnology, pp. 127-140. Edited by J. R. Whitaker \& P. E. Sonnet. Washington, DC: American Chemical Society.

Hopwood, D. A., BibB, M. J., Chater, K. F., Kieser, T., Bruton, C. J., Keiser, H. M., Lydiate, D. J., Smith, C. P., Ward, J. M. \& 
SCHREMPF, H. (1985). Genetic Manipulation of Streptomyces. A Laboratory Manual. Norwich: John Innes Foundation.

HUYNH, V.-B. \& CRAWFORD, R. L. (1985). Novel extracellular enzymes (ligninases) of Phanerochaete chrysosporium. FEMS Microbiology Letters 28, 119-123.

KERSTEN, P. J. \& KIRK, T. K. (1987). Involvement of a new enzyme, glyoxal oxidase, in extracellular $\mathrm{H}_{2} \mathrm{O}_{2}$ production by Phanerochaete chrysosporium. Journal of Bacteriology 169, 2195-2201.

KeYSER, P., KIRK, T. K. \& ZEIXUS, J. G. (1978). Ligninolytic enzyme system of Phanerochaete chrysosporium: synthesized in the absence of lignin in response to nitrogen starvation. Journal of Bacteriology 135 , 790-797.

KIRK, T. K. \& FARRELL, R. L. (1987). Enzymatic 'combustion': the microbial degradation of lignin. Annual Review of Microbiology 41, 465-505.

Kirk, T. K., Tien, M., Kersten, P. J., Mozuch, M. D. \& Kalyanaraman, B. (1986). Ligninase of Phanerochaete chrysosporium: mechanism of its degradation of the non-phenolic arylglycerol$\beta$-aryl ether substructure of lignin. Biochemical Journal 236, 279-287.

LodHa, S. J., Korus, R. A. \& Crawford, D. L. (1991). Synthesis and properties of lignin peroxidase from Streptomyces viridosporus T7A. Applied Biochemistry and Biotechnology 28, 411-420.

MacDonald, D. L., Stanier, R. Y. \& Ingraham, J. L. (1954). The enzymatic formation of $\beta$-carboxymuconic acid. Journal of Biological Chemistry 210, 809-820.

MCCARTHY, A. J. (1987). Lignocellulose-degrading actinomycetes. FEMS Microbiology Reviews 46, 145-163.

MCCARTHY, A. J. \& BRODA, P. (1984). Screening for lignin-degrading actinomycetes and characterization of their activity against $\left[{ }^{14} \mathrm{C}\right]$ lignin-labelled wheat lignocellulose. Journal of General Microbiology 130, 2905-2913.

McCarthy, A. J., Paterson, A. \& Broda, P. M. A. (1986). Lignin solubilisation by Thermomonospora mesophila. Applied Microbiology and Biotechnology 24, 347-352.

Magnuson, T. S., Roberts, M. A., Crawford, D. L. \& Hertel, G. (1991). Immunologic relatedness of extracellular ligninases from the actinomycetes Streptomyces viridosporus T7A and Streptomyces badius 252. Applied Biochemistry and Biotechnology 28, 433-443.

Miki, K., Renganathan, V. \& Gold, M. H. (1986). Mechanism of $\beta$ aryl ether dimeric model lignin compound oxidation by lignin peroxidase of Phanerochaete chrysosporium. Biochemistry 24, 47904796.

Ramachandra, M., Crawford, D. L. \& Pometto, A. L. (1987). Extracellular enzyme activities during lignocellulose degradation by Streptomyces spp.: a comparative study of wild-type and genetically manipulated strains. Applied and Environmental Microbiology 53, 2754-2760.

Ramachandra, M., Crawford, D. L. \& Hertel, G. (1988). Characterisation of an extracellular lignin peroxidase of the lignocellulolytic actinomycete Streptomyces viridosporus. Applied and Environmental Microbiology 54, 3057-3063.

Ruttimann, C., Seelenfreund, D. \& Vicuña, R. (1987). Metabolism of low molecular weight lignin-related compounds by Streptomyces viridosporus T7A. Enzyme and Microbial Technology 9, 526-530.

Stanier, R. Y. \& INGRaham, J. L. (1954). Protocatechuic acid oxidase. Journal of Biological Chemistry 210, 799-808.

Sutherland, J. B., Crawford, D. L. \& Pometro, A. L., III (1983). Metabolism of cinnamic, $p$-coumaric, and ferulic acids by Streptomyces setonii. Canadian Journal of Microbiology 29, 1253-1257.

TIEN, M. (1987). Fungal lignin peroxidases. CRC Critical Reviews in Microbiology 15, 141-168.

TIEN, M. \& KIRK, T. K. (1983). Lignin-degrading enzyme from the hymenomycete Phanerochaete chrysosporium Burds. Science 221, 661-663.

Vicuña, R. (1988). Bacterial degradation of lignin. Enzyme and Microbial Technology 10, 646-655.

Wang, Z., Bleakley, B. H., Crawford, D. L., Hertel, G. \& Rafi, F. (1990). Cloning and expression of a lignin peroxidase gene from Streptomyces viridosporus in Streptomyces lividans. Journal of Biotechnology 13, 131-144.

ZIMMERMANN, W. (1990). Degradation of lignin by bacteria. Journal of Biotechnology 13, 119-130. 